\title{
An Empirical Evaluation of Consumption Behaviour in Oil Societies: The Case of Kuwait
}

\author{
SULAYMAN S. AL-QUDSI*
}

Theories of consumption function have been tested for many developed and underdeveloped economies with grouped data sets. No empirical work has been done to confirm or disconfirm these theories in the oil-rich economies of the Middle East. This paper applies Kuwait's rich micro data of the 1972-73 budget survey results to the principal consumption models - the Keynesian Model, the Kaldor Hypothesis, the Friedman Permanent-Income Model and the Life-Cycle Hypothesis. The results of this empirical investigation disconfirm the validity of the strict version of the Permanent-Income Hypothesis in favour of the Keynesian and the looser version of the Permanent-Income Hypotheses. The Kaldor model is not strictly applicable and the saving behaviour of Kuwaiti households seems to give support to the Life-Cycle Hypothesis.

\section{INTRODUCTION}

Theories of consumption function have been tested for many developed and underdeveloped countries for the sake of confirming or disconfirming their validity. ${ }^{1}$ However, little work has been done to test the relative validity of these functions in the oil-rich economies of the Middle East. Moreover, a substantial part of available empirical tests is performed on aggregate data. This paper uses microdata to test the principal consumption models in the case of an oil-rich economy, Ku'vait. The data base we have is the $1972-73$ family budget survey [5]. The survey was planned by the Planning Bureau of Kuwait in conjunction with a team of economists and sociologists from the Stanford Research Institute. The stratified sample comprised 1,160 households - single-member households were excluded - which represents about 1.2 percent of the total households living in the country during the survey

${ }^{\star}$ Mr. Sulayman S. al-Qudsi is a member of Economics Department, Techno Economics Division, Kuwait Institute for Scientific Research, Box 24885, Safat, Kuwait. The author would like to thank Thomas Mayer, Ismail Sirageldin, and an anonymous referee for their comments on earlier drafts. The remaining errors are those of the author.

${ }^{1}$ See, for example, Mayer [8], Blinder [1], Singh, Drost and Kumar [15], and Song 
period. Of the 1,160 observations, 481 were Kuwaitis and 679 were non-Kuwaitis On the average, a Kuwaiti family has eight members while a non-Kuwaiti family has six. Thus, the nationality breakdown in the sample is similar to the actual population breakdown in the early 1970s (47\% Kuwaitis and 53\% non-Kuwaitis). We were fortunate to obtain from the Ministry of Planning the Computerized Raw Data on each of the 1,160 observations. Our analysis below is based on these microdata.

Some background of the Kuwaiti economy is presented to set the stage for the analysis that follows.

\section{BACKGROUND}

Following World War II, Kuwait became a major supplier of oil to industrialized nations. This resulted in her acquisition of a huge amount of financial resources. It also resulted in changes in her product and labour markets. In the product market the economy became oil-based and experienced rapid growth, with an average annual rate of growth of 15 percent [6]. Per capita income became one of the highest in the world $-\$ 11,000$ in 1974 and $\$ 21,000$ in 1980. But despite serious efforts to diversify the sources of income, the economy remains heavily dependent on oil: over the 1962-1975 period oil's share in Gross Domestic Product (GDP) was 73 percent. In the labour market, high annual immigration rates produced a persistent contradiction in the country's population mix and in its labour force: Kuwaitis are increasingly becoming a shrinking minority in their own country. In 1957 they made up 55 percent of the total population; in the years 1961, 1975, and 1980, their share in the total population decreased to 50.4 percent, 47.5 percent and 41.0 percent respectively [4]. Non-Kuwaitis make up about 70 percent of the total labou force. This results from interrelated factors. The small and young population, the low participation rate of Kuwaiti women, the aversion of many Bedouins to manua labour and the expansion of welfare and educational systems meant that the supply of labour from the indigenous population fell short of the drastic increase in labour demand which ensued from the oil boom of the 1960s and 1970s.

While non-nationals are indeed the cornerstone of the development pro gramme, their presence was bound to have a bearing on two factors that Kuznets identified as crucial features of successful small nations: the society's internal homogeneity and the degree of egalitarianism in the distribution of income [7].

The distributional pattern that emerged in the country in the early 1970 s points to a moderate inequality: the richest decile gets 35.5 percent of the tota income, consumes 26 percent of the total consumption, earns 22.3 percent of the total wage and salary payments, and receives 79 percent and 96 percent of the tota business and property incomes, respectively, and about 53 percent of the total in come from stock investments.
The poorest decile, on the other hand, receives just below two percent of the total income, consumes 2.8 percent of the society's total consumption, earns 2.3 percent of the total wage and salary bill, and receives two-tenths and nine-tenths of one percent of society's business and property income and nothing of the society's income from bonds and securities. Mean income of a non-Kuwaiti family is about 57 percent of the corresponding income of a Kuwaiti family. Kuwaiti families receive 48.3 percent of the total wage income, 57 percent of the total business income, 100 percent of the total property income (non-Kuwaitis are not allowed to own property) and about 65 percent of the total stocks and securities income. Inequality is more pronounced among Kuwaitis than among non-Kuwaitis (the Gini Coefficient ${ }^{2}$ for the former is .467 compared with .393 for the latter) as Table 1 demonstrates.

\section{ESTIMATING THE ECONOMY'S CONSUMPTION FUNCTION}

The principal existing models may be classified into the standard Keynes Model, the Friedman Permanent Income Model, the Kaldor Model and the ModiglianiBrumberg Life-Cycle Hypothesis Model. To test the Keynesian model, we employ two functional forms: one quadratic, and the other log-linear:

$$
\begin{aligned}
& H_{0}: \beta_{2}=0 \\
& H_{a}: \beta_{2} \neq 0
\end{aligned}
$$$$
\operatorname{LnC} C_{i}=\beta_{0}+\beta_{1} \operatorname{Ln} Y_{i}+\epsilon_{i} \quad i=1 \ldots n \quad \ldots \quad \ldots
$$

According to (2.1), the marginal propensity to consume equals $\left(\beta_{1}+2 \beta_{2} Y_{i}\right)$. Our null hypothesis is then

If we reject the null hypothesis, then linearity in our data does not exist (i.e. the function would be quadratic).

With the functional form (2.2), the marginal propensity to consume is $\frac{d c}{d y}=A B_{1} Y^{\beta_{1}-1}$

where $\ln A=B_{0}$. We test the null hypothesis that $\beta_{1}=1.0$. If $\beta$ is statistically smaller than one, then the consumption level decreases as income increases (i.e. there would be a negative effect of equity on savings and hence on growth).

${ }^{2}$ The Gini coefficients were computed with the help of the following formula: $G=1+\left(\frac{1}{n}\right)-\left(2 / n^{2} \mu\right)\left[y_{1}+2 y_{2}+\ldots+n y_{n}\right]$, for $y_{1} \geqslant \ldots \geqslant y_{n}$ Sce Sen $\{14\}$. 


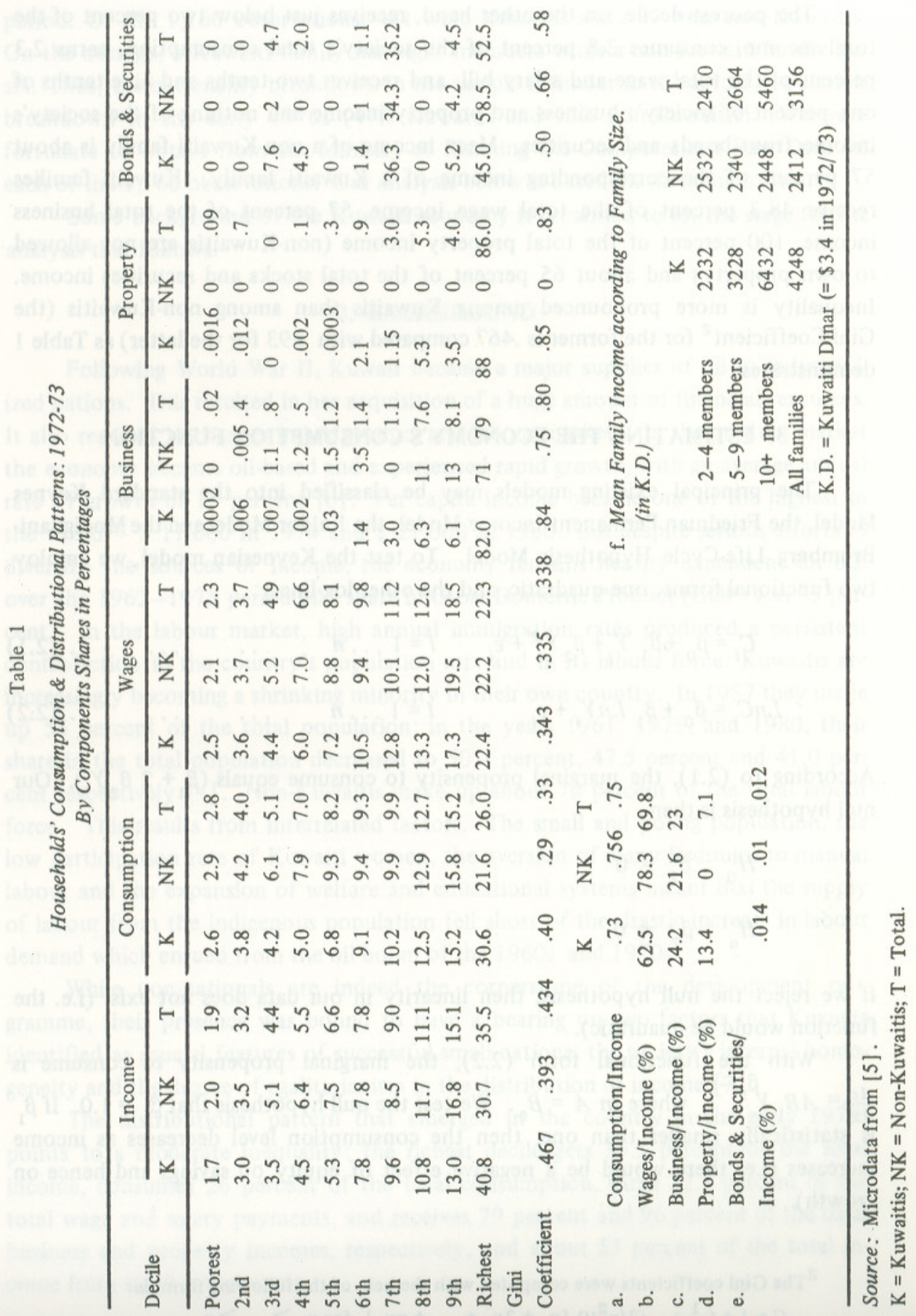

Before carrying out tests with (2.1) and (2.2), we used Park's Procedure to make suitable adjustments for heteroscedasticity in our data. ${ }^{3}$ Hence, our tests below utilize the Generalized Least Squares technique.

Table 2 shows the results of the functional forms chosen to test the measured income hypothesis. The statistical significance of the term $\left(Y^{2}\right)$ indicates that the consumption function is curvilinear, i.e. the function is quadratic. This in turn gives support to the hypothesis that a redistributive effect does indeed exist. Also notice that the coefficient of the independent variable in (2.2) is statistically significant The null hypothesis that $\beta_{1}=1$ is rejected in all the regression models which employ equation (2.2). The values of the t-tests are $-18,-14.4$ and -15.6 for the Total, Kuwaiti and non-Kuwaiti consumption functions respectively. ${ }^{4}$ This gives support to the existence of a redistributive effect, i.e. a more equitable distribution would decrease savings.

We ran three regression equations; linear, quadratic and log-linear to test the Kaldor hypothesis: ${ }^{5}$

(1) $C_{i}=\alpha+\beta y_{i}+\delta M_{i}+\epsilon_{i}$

(2) $C_{i}=\alpha+\beta y_{i}+\gamma y_{i}^{2}+\delta M_{i}+\epsilon_{i}$

(3) $L n c_{i}=\alpha+\beta L n y_{i}+\delta M_{i}+\epsilon_{i}$

where $C_{i}, y_{i}, y_{i}^{2}$ are as defined before, and $M_{i}=\left\{\begin{array}{l}1 \text { if the } i \text { th person is self-employed } \\ 0 \text { if the } i \text { th person is wage earner. }\end{array}\right.$

${ }^{3}$ The employed test is a Park's test where the equation $Y_{i}=\beta_{0}+\beta_{1} X_{i}+U_{i}, \quad i=1,2, \ldots N \ldots$ (1)

was estimated first by the Ordinary Least Squares Method. $\hat{U}_{i}^{2}$ were then used as estimates of the variance in the equation

$$
\sigma \mu_{i}^{2}=\sigma^{2} X_{i}^{\gamma} e^{v}
$$

and estimates of $\gamma, \sigma_{2}$ were obtained and finally the original equation (1) was transformed as follows.

$$
\left(\frac{Y_{i}}{X_{i} \hat{\gamma} / 2}\right)=\beta_{\mathrm{o}}\left(\frac{1}{X_{i} \hat{\gamma} / 2}\right)+\beta_{1} X_{i}^{-\hat{\gamma} / 2} \quad v^{\star} \ldots \text { (2) }
$$

and the estimated value of $\hat{\gamma}$ was found to be 1. See R. E. Park [10]

$\beta_{1}-1$ cient of equation (2.2).

Wheression coeffi-

${ }^{5}$ W. Cline [3] rejects the Kaldor Hypothesis in four Latin American countries. However, he uses aggregate income and consumption data. 


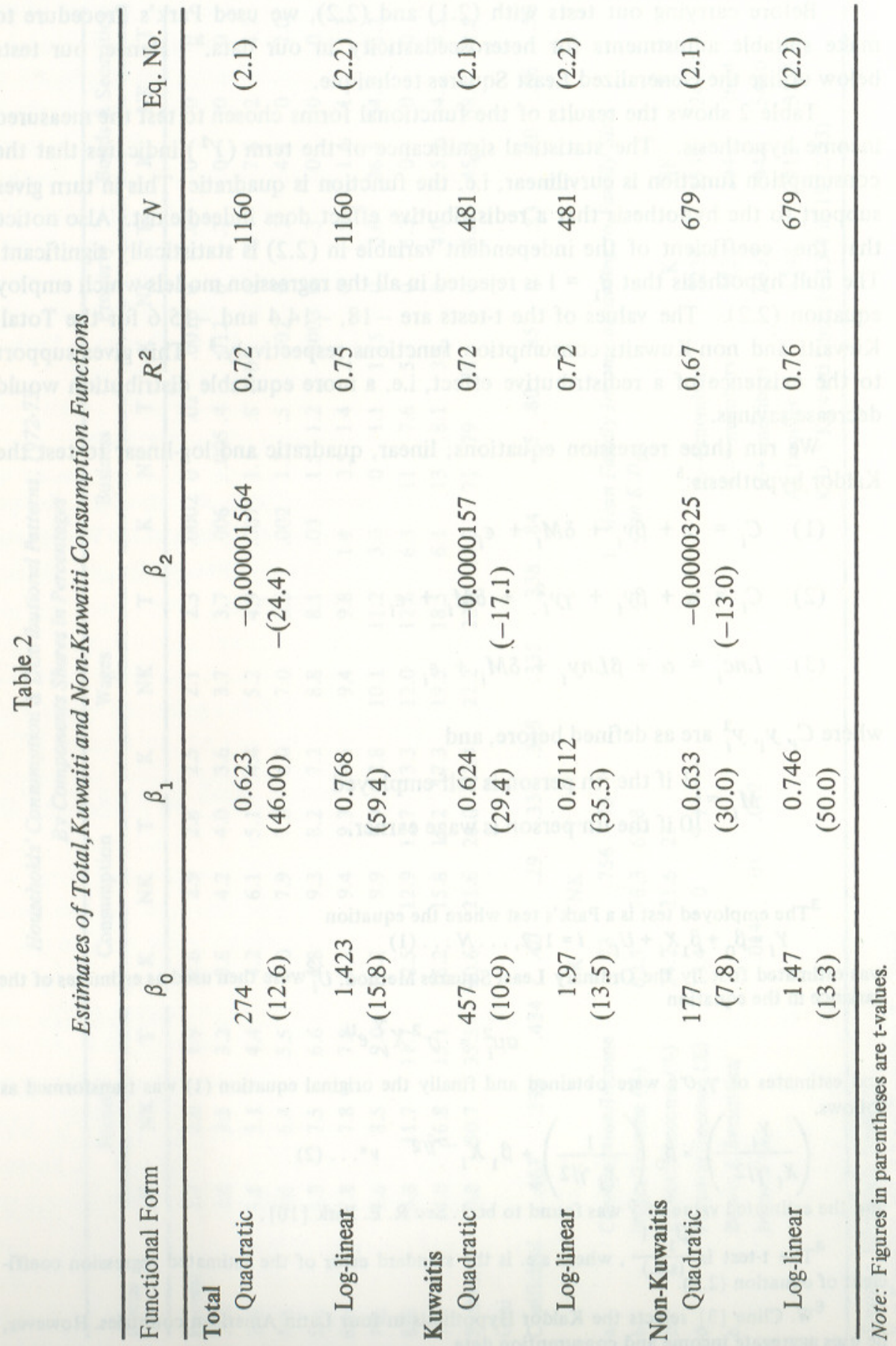

The results of this estimation procedure are given in Table 3.

The dummy variable for the source of income (i.e. self-employed, wage earner) is insignificant at the 5-percent level when the employed functional form is linear. However, it becomes statistically significant when a quadratic model is specified, particularly when the function is log-linear. Based on these results, it appears to us that the source of income has some bearing on consumption. Redistribution from property owners to wage earners would tend to increase consumption.

Table 3

Testing the Kaldor Hypothesis

\begin{tabular}{lcccccc}
\hline Functional & \multicolumn{5}{c}{ Coefficients } \\
\cline { 2 - 7 } & \multicolumn{1}{c}{$\alpha$} & $\beta$ & \multicolumn{1}{c}{$\gamma$} & $\delta$ & $R^{2}$ & $N$ \\
\hline Linear & 597 & 0.35 & & -58 & 0.57 & 1160 \\
& $(27.7)$ & $(37.8)$ & & $(-1.1)$ & & \\
Quadratic & 279 & 0.632 & -.0000158 & -123 & 0.72 & 1160 \\
& $(12.8)$ & $(45.7)$ & $(-25)$ & $(-2.9)$ & & \\
Log-linear & 1.27 & 0.76 & & -0.10 & 0.75 & 1160 \\
& $(14.0)$ & $(58.0)$ & & $(-3.5)$ & & \\
\hline
\end{tabular}

Note: $\quad$ Figures given in parentheses are t-values.

But is there any statistical difference at all between the marginal and average propensities to consume? A permanent-income theorist would give a "no" for an answer to this question.

According to the permanent-income approach, consumption depends upon "permanent" income; transitory income is saved. "The permanent income theory claims that the income elasticity of savings is about unity, i.e. that households with high and low permanent income save, on the average, the same proportion of their permanent incomes" [13]. Our next task is, then, to investigate this issue more carefully. There are two versions of the permanent-income hypothesis:

1. The strict version, which asserts that the elimination of the statistical bias, introduced by the use of measured income as the independent variable, shifts the consumption function to such an extent that the marginal and average propensities to consume permanent income are independent of the level of permanent income. Consequently, the implied relationship is linear with a zero intercept. The strict version of 
the permanent-income hypothesis implies that redistribution does not affect society's total savings.

2. The looser version hypothesizes that the marginal propensity to consume measured income is smaller than the marginal propensity to consume permanent income. However, this version acknowledges that even for permanent income, the marginal propensity is less than the average propensity [8]. The specific premise that we need to test here is in terms of the following hypothesis:

$H_{o_{s}}: A P C_{p}=M P C_{p}$, the average propensity to consume permanent income equals the marginal propensity to consume permanent income. This is the strict version of the permanent-income theory.

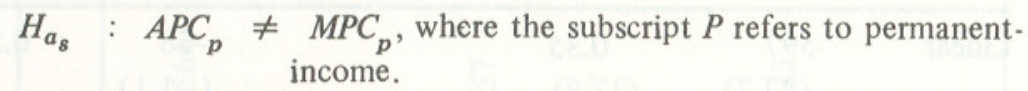
Two statistical tests are used to test $H_{o_{s}}$. They are:

(i) The setting up of confidence intervals for the point estimates of the coefficients in the two relations. If the intervals do not overlap, then we reject $H_{o}$. If the intervals overlap, then there is no evidence to reject $H_{o_{s}}$.

(ii) The use of the Chow test to determine whether there exists equality between the sets of coefficients estimated from the functions based on measured and permanent income. $H_{o}$, in this case, is similar to a hypothesis of equality between the sets of coefficients ${ }^{s}$ [2]. Rejecting $H_{o s}$ gives rise to testing $H_{a_{s}}$ (i.e. the looser version of the permanent-income hypothesis). A simple procedure for testing the looser version is as follows. If the functional form is linear, the procedure consists of computing the marginal propensity to consume twice, once from households grouped by nationality and again from the same households grouped by income (i.e. by measured income). If the permanent-income theory is entirely correct, then the marginal propensity to consume, when computed from the nationality grouping, should equal the average propensity to consume. On the other hand, assume that the permanent-income theory is completely wrong, and that it makes no difference whether we use permanent income or measured income in estimating the consumption function. In that case, the marginal propensity to consume should be the same when households are classified by measured income or by permanent income.

Mayer [9] devised a prediction coefficient which illustrates the above alternatives. It can be described as follows:

$$
P=\frac{M P C_{p}-A P C}{M P C_{m}-A P C}
$$

where $P$ is the Mayer Prediction Coefficient, $M P C_{p}$ is the marginal propensity to consume permanent income, $A P C$ is the average propensity of consumption and $M P C_{m}$ is the marginal propensity to consume measured income. If the permanent-income hypothesis is entirely correct, the prediction coefficient would take a zero value, since in that case $M P C_{p}=A P C . \quad P$ would be equal to unity if the measured-income hypothesis is entirely correct. If $0<P<1$, the looser version of the permanentincome hypothesis has some validity.

There are various proxies for permanent income in cross-section tests : some combination of occupation, education, age and race (nationality). The idea is simple. One may look upon the average consumption of all households that have the same occupation, race (nationality), age group, or level of education as proxy for permanent consumption within that occupation (race, age, or educational level) Similarly, the average income of certain groups in each of the above categories may be looked upon as a proxy for the groups' permanent income. Econometric estimates showed that nationality is of paramount importance in income determination in Kuwait. As such, we feel that it is a good proxy for permanent income and consumption. All in all, we distinguished between 12 nationalities in Kuwait [12] . The average consumption level of each nationality is regressed against the nationality's average income level. These consumption-income observations, which are based on nationality groupings, are then compared with consumption-income observations which are based on grouped means. Two functional forms - linear and $\log$-linear - are employed to test the above hypothesis. Table 6 provides the results of our estimation procedure. The results show that the intervals of the coefficients derived from an income class do not overlap with the intervals set up for the coefficients derived from nationality grouping. In the linear functional form, the marginal propensity to consume out of permanent income is higher than that out of measured income. Under conditions of log-linearity, the same type of comparison between confidence intervals indicates again that there is little or no overlap between the confidence intervals, as Table 4 shows. Based on this test, we reject the null hypothesis $H_{o_{s}}$ in favour of the alternative hypothesis, $H_{a_{s}}$.

The results of the Chow test for both linear and log-linear functional forms are presented in Table 5. Under conditions of linearity, $H_{o}$ is rejected in both cases at a 5-percent level of significance (i.e. $F>F$ 0.05). A similar result obtains when the log-linear functional forms are employed. On the other hand, Mayer's Prediction Coefficient indicates that there is validity in the looser version of the permanent-income hypothesis. In the case of the linear consumption functions, the coefficient is positive but less than one as Table 6 demonstrates. With the log-linear consumption functions, the ratio $\left(M P C_{p} / M P C_{m}\right)$ is greater than one $(.871 / .792=1.1)$. 
Table 4

Confidence Intervals for the Coefficients of the Permanent and Measured Consumption Functions

\begin{tabular}{|c|c|c|c|c|c|}
\hline Grouping & $\begin{array}{c}\text { Functional } \\
\text { Form }\end{array}$ & $\begin{array}{l}\text { Param } \\
\text { Estima }\end{array}$ & & $\begin{array}{l}\text { Standard } \\
\text { Error }\end{array}$ & $\begin{array}{c}\text { Confidence } \\
\text { Interval }\end{array}$ \\
\hline \multirow[t]{4}{*}{ Income } & Linear & Intercept $=$ & 523.0 & 109 & $309-737$ \\
\hline & & Coefficient $=$ & 0.50 & 0.0385 & $0.424-0.575$ \\
\hline & Log-linear & Intercept $=$ & 1.36 & 0.25 & $0.87-1.85$ \\
\hline & & Coefficient $=$ & 0.79 & 0.0333 & $0.76-0.98$ \\
\hline \multirow[t]{4}{*}{ Nationality } & Linear & Intercept $=$ & 120.0 & 55 & $12.2-228$ \\
\hline & & Coefficient $=$ & 0.63 & 0.0403 & $0.55-0.71$ \\
\hline & Log-linear & Intercept $=$ & 0.60 & 0.41 & $-0.20-1.41$ \\
\hline & & Coefficient $=$ & 0.87 & 0.0585 & $0.76-0.98$ \\
\hline
\end{tabular}

Table 5

F-Statistics for the Chow Test of Equality between Coefficients of Consumption Functions from Measured and Permanent Income

\begin{tabular}{lcc}
\hline & Linear & Log-linear \\
\hline SSE & 51759 & .05799 \\
SSE & 839000 & .0508 \\
SSE & 1758911 & .4110 \\
$\mathrm{Q}_{3} / \mathrm{K}$ & 434076 & .151 \\
$\mathrm{Q}_{2} /(\mathrm{nl}+\mathrm{n} 2-2 \mathrm{~K})$ & 54259 & .0068 \\
$\mathrm{~F}$ & 8.0 & 22.2 \\
$\mathrm{~F} 0.05$ & 3.55 & \\
\hline Note: $Q_{3}=\Sigma e^{2}-\left(\Sigma e^{2}+\Sigma e^{2}\right)$ and $Q_{2}=\Sigma e^{2}+\sum e^{2}$
\end{tabular}

Note: $Q_{3}=\Sigma e_{T}^{2}-\left(\Sigma e_{p}^{2}+\Sigma e_{m}^{2}\right)$ and $Q_{2}=\Sigma e_{p}^{2}+\Sigma e_{m}^{2}$, where subscripts $p$,

$m, T$ refer to permanent, measured and pooled consumption functions.
Table 6

Testing Permanent \& Measured Income Hypotheses using Group Means

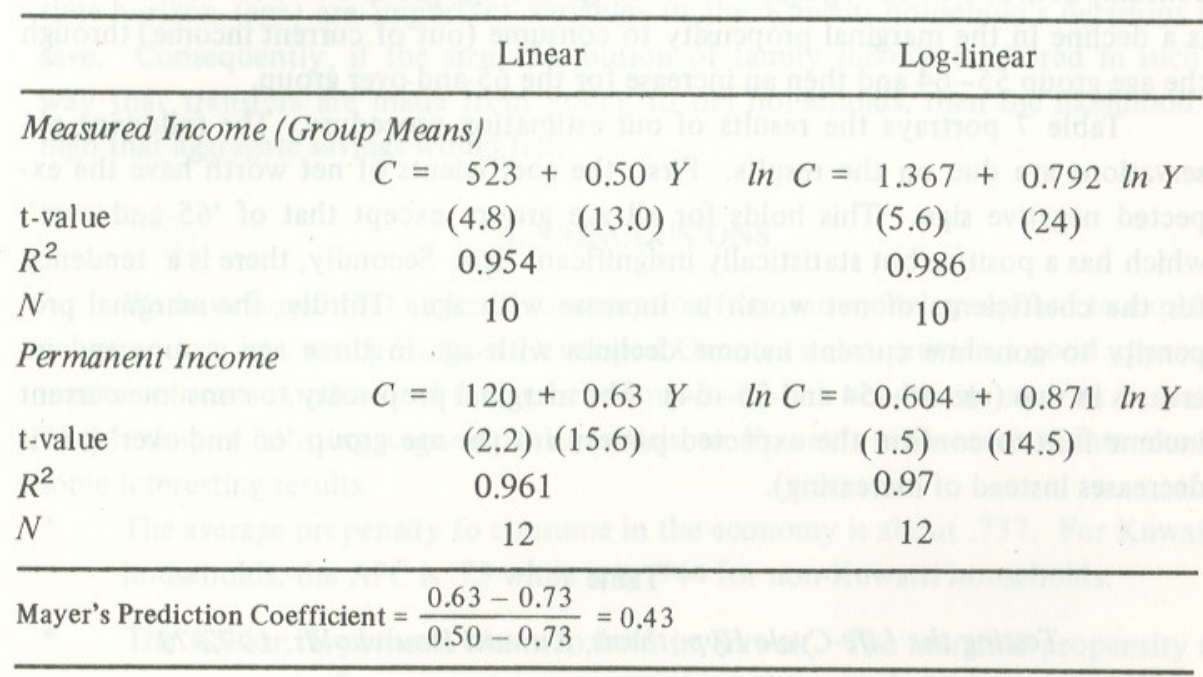

As ownership of non-human wealth, noticeably land and housing, is restricted by law to Kuwaitis, we restrict our test of the Life-Cycle Hypothesis to Kuwaiti families only. Following Projector's estimation procedure [11], we employ the following functional form:

$$
c_{i j}=\alpha+\beta y_{i j}+\delta N w_{i j}+\epsilon_{i j}
$$

where

$C_{i j}$ is the consumption level of the $i$ th family whose head is in the $j$ th age group - the sample was divided into five age groups (20-34, 35-44, 45-54, 55-64 and 65 and over);

$Y_{i j}$ is the current-income level of the $i$ th family whose head is in the $j$ th age group,

$N W_{i j}$ is the net worth of the $i$ th family whose head is in the $j$ th age group, the net worth being defined to include assets (housing value, business, and/or value of bonds and securities), and

$\epsilon_{i j}$ is the disturbance term.

According to the Life-Cycle Hypothesis, in a cross-section at one point in time, younger consumers will be observed to spend a smaller fraction of their current net worth than older units, given the sum of current and expected future earnings, 
because older units have fewer years over which a given amount of resources must extend. On the other hand, the ratio of current and future earnings to permanent income will decline with age and will apparently more than offset the increase in consumption due to the aging factor through the age group 55-64. The net result is a decline in the marginal propensity to consume (out of current income) through the age group 55-64 and then an increase for the 65-and-over group.

Table 7 portrays the results of our estimation procedure. The following observations are due on the results. First, the coefficients of net worth have the expected negative sign. This holds for all age groups except that of ' 65 and over', which has a positive but statistically insignificant sign. Secondly, there is a tendency for the coefficients of net worth to increase with age. Thirdly, the marginal propensity to consume current income declines with age in three age groups and increases in two (viz. 45-54 and 55-64). The marginal propensity to consume current income fails to confirm the expected pattern for the age group ' 65 and over' (i.e. it decreases instead of increasing).

Table 7

Testing the Life-Cycle Hypothesis, Kuwaiti Households: 1972-73

\begin{tabular}{lccccc}
\hline Age Group & Constant & $M P C_{\mathbf{Y}}$ & $M P C_{N W}$ & $R^{2}$ & $N$ \\
\hline Total Units & 365 & 0.30 & -0.17 & 0.65 & 481 \\
& $(10.5)$ & $(20.0)$ & $(-15.2)$ & & \\
65 and over & 680 & 0.18 & 0.04 & 0.57 & 29 \\
& $(3.1)$ & $(4.1)$ & $(0.34)$ & & \\
$55-64$ & 290 & 0.37 & -0.18 & 0.82 & 56 \\
& $(2.6)$ & $(12.8)$ & $(-5.1)$ & & \\
$45-54$ & 500 & 0.30 & -0.22 & 0.58 & 98 \\
& $(5.2)$ & $(14.0)$ & $(-8.0)$ & & \\
$35-44$ & 480 & 0.24 & -0.14 & 0.65 & 180 \\
& $(11.0)$ & $(13.0)$ & $(-6.0)$ & & \\
$25-34$ & $(3.1)$ & $(21.0)$ & $(-7.1)$ & & \\
\hline
\end{tabular}

Note: Figures in parentheses are t-values.
A tentative conclusion may be drawn as follows. The data seem to be in accord with some parts of the Life-Cycle Hypothesis but not with the whole predicted pattern. For income redistribution purposes, it appears to us, based on the L.C.H. test above, that there is enough evidence to suspect that both net wealth and time-horizon (age) are important variables in the Kuwaiti household's decisions to save. Consequently, if the size distribution of family income is altered in such a way that transfers are made from young to old households, then the likelihood is high that aggregate savings would fall.

\section{CONCLUSIONS}

We have found that all basic consumption function models proposed to explain consumption and saving in Most Developed Countries also provide a good approximation of consumption and saving behaviour in oil-rich economies such as Kuwait. The fitting of existing consumption models to Kuwait's cross-section data shows some interesting results:

* The average propensity to consume in the economy is about .737. For Kuwaiti households, the APC is .73 while it is .744 for non-Kuwaiti households.

* The Kaldor Hypothesis seems to hold in Kuwait. The marginal propensity to consume out of property income as estimated by the Kaldor model in Table 3 is $.66-.69$, much smaller than the marginal propensity to consume nonproperty income $(.76-.79)$. A redistribution of income from wealth owners (basically the top 20 percent of Kuwaitis) to wage earners (almost all nonKuwaitis except the top decile group and the poorest 40 percent of Kuwaitis) is likely to generate some consumption increase.

* The strict version of the permanent-income hypothesis is not supported by Kuwait's data. However, both the looser version and the measured-income theories have some validity, implying that a reversal of the current unequal distributional pattern is likely to increase consumption.

* The saving behaviour of Kuwaiti households varies with the age of the household, giving some support to the Life-Cycle Hypothesis. Accordingly, political decisions that aim at altering the economy's consumption behaviour must take the age structure into account.

\section{REFERENCES}

1. Blinder, A. "Distributional Effects and the Aggregate Consumption Function". Journal of Political Economy. Vol. 83, No. 3. June 1975.

2. Chow, G. C. "Tests of Equality between Sets of Coefficients in Two Linear Regressions". Econometrica. Vol. 28. February 1960. 
3. Cline, W. Potential Effects of Income Redistribution on Economic Growth: Latin American Cases. New York: Praeger. 1972.

4. Kuwait. Ministry of Planning. Annual Statistical Abstract. Kuwait. 1981.

5. Kuwait. Ministry of Planning, Budget Survey Results 1972-73. Kuwait.

6. Kuwait. Ministry of Planning. Central Statistical Office. National Accounts Statistics. Kuwait. February 1982.

7. Kuznets, S. "Economic Growth of Small Nations". In E.A.G. Robinson (ed.), Economic Consequences of the Size of Small Nations. New York: Macmillan. 1960.

8. Mayer, T. Permanent Income, Wealth and Consumption: A Critique of the Permanent Income Theory, the Life Cycle Hypothesis and Related Theories. Berkeley: University of California Press. 1972.

9. Mayer, T. "The Propensity to Consume Permanent Income". American Economic Review. Vol. 56, No. 5. December 1966.

10. Park, R. E. "Estimation with Heteroscedastic Error Terms". Econometrica. Vol. 34, No. 4. October 1966.

11. Projector, D. Survey of Changes in Family Finances. Washington, D.C.: Board of Governors of the Federal Reserve System. 1968.

12. al-Qudsi, S. "Earnings Difference in the Labor Markets of Arab Gulf States - The Case of Kuwait". Journal of Development Economics. (Forthcoming)

13. Rowan, D., and T. Mayer. Intermediate Macroeconomics. New York: W. Norton and Co. 1972.

14. Sen, A. On Economic Inequality. London : Oxford University Press. 1973.

15. Singh, B., H. Drost and R. C. Kumar. "An Empirical Evaluation of the Relative, the Permanent Income, and the Life-Cycle Hypothesis". Economic Development and Cultural Change. Vol. 26, No. 2. January 1978.

16. Song, B. "Empirical Research on Consumption Behavior: Evidence from Rich and Poor LDC's". Economic Development and Cultural Change. Vol. 29, No. 3. 1981. 